\title{
A Normative Study of the Digit Span in an Educationally Diverse Elderly Population
}

\author{
Hyo Jung Choi', Dong Young Lee ${ }^{1,2} \llbracket$, Eun Hyun Seo ${ }^{2}$, Min Kyung Jo', Bo Kyung Sohn', \\ Young Min Choe', Min Soo Byun ${ }^{1}$, Jee Wook Kim ${ }^{3}$, Shin Gyeom Kim", Jong Choul Yoon ${ }^{5}$, \\ Jin Hyeong $\mathrm{Jhoo}^{6}$, Ki Woong $\mathrm{Kim}^{7}$, and Jong Inn Woo ${ }^{1,2}$
}

${ }^{1}$ Department of Neuropsychiatry and ${ }^{2}$ Interdisciplinary Program for Cognitive Science, Seoul National University Hospital, Seoul, Republic of Korea ${ }^{3}$ Department of Neuropsychiatry, Hallym University Dongtan Sacred Heart Hospital, Hwaseong, Republic of Korea

${ }^{4}$ Department of Neuropsychiatry, Soonchunhyang University Bucheon Hospital, Bucheon, Republic of Korea

${ }^{5}$ Department of Neuropsychiatry, Gyeonggi Provincial Hospital for the Elderly, Yongin, Republic of Korea

${ }^{6}$ Department of Psychiatry, Kangwon National University Hospital, Chuncheon, Republic of Korea

${ }^{7}$ Department of Neuropsychiatry, Seoul National University Bundang Hospital, Seongnam, Republic of Korea

Objective The purpose of this study was to explore the effect of demographic variables on Digit Span test (DS) performance in an educationally diverse elderly population and to provide normative information.

Methods The DS was administered to 784 community-dwelling volunteers aged 60-90 years with an educational history of from zero to 25 years of full-time education. People with serious neurological, medical and psychiatric disorders (including dementia) were excluded.

Results Age, education and gender were found to be significantly associated with performance on the DS. Based on the results obtained, DS norms were stratified by age ( 2 strata), education ( 3 strata), and gender ( 2 strata).

Conclusion Our results on DS performance suggest that both attention and working memory are influenced by age, education and gender. The present study provides reasonably comprehensive normative information on the DS for an educationally diverse elderly population.

Psychiatry Investig 2014;11:39-43

Key Words Neuropsychological tests, Reference standards, Age factors, Education, Sex, Koreans.

\section{INTRODUCTION}

The Digit Span test (DS) is a widely used neuropsychological measure, known as a test of attention and working memory. ${ }^{1-5}$ The DS consists of forward recall part and backward recall part for digit sequences. Each part is considered to assess somewhat different cognitive processes. Although specific cognitive components contributing to each part of the DS performance are not well-defined, the DS forward is regarded to be more related to attention and the DS backward is to work-

Received: April 18, 2013 Revised: June 17, 2013

Accepted: June 25, 2013 Available online: October 16, 2013

$\triangle$ Correspondence: Dong Young Lee, MD, PhD

Department of Neuropsychiatry, Seoul National University Hospital, 101 Daehak-ro, Jongno-gu, Seoul 110-744, Republic of Korea

Tel: +82-2-2072-2205, Fax: +82-2-762-3176, E-mail: selfpsy@snu.ac.kr

(a) This is an Open Access article distributed under the terms of the Creative Commons Attribution Non-Commercial License (http://creativecommons.org/licenses/by$\mathrm{nc} / 3.0$ ) which permits unrestricted non-commercial use, distribution, and reproduction in any medium, provided the original work is properly cited. ing memory. ${ }^{1,6}$

The DS is very useful in clinical settings to differentiate, monitor, and describe various neuropsychiatric or cognitive disorders including dementia, depression, and malingered neurocognitive dysfunction. ${ }^{7-9}$ The DS also can be applied to assess people handicapped by illiteracy. ${ }^{10,11}$

DS performance has been found to be influenced by demographic factors. The relationship between older age and reduced performance has been consistently reported. ${ }^{12-14}$ Educational level is also known to have a positive effect on DS performance. ${ }^{15-17}$ However, the effect of gender on DS score is controversial. Some studies reported a minimal or no gender effect, suggesting that no gender corrections need to be applied to normative data, ${ }^{5,18}$ while other studies showed significantly higher DS backward performance in female than in male. $^{19}$

Although several DS norms have been reported, many of them were obtained from relatively small number of elderly 
participants with a limited educational background. ${ }^{3}$ Most normative studies for DS performance in older people targeted mainly highly educated individuals (more than 12 years). ${ }^{13,14,18,20}$ while very limited numbers of studies investigated the influences of demographic factors and normative corrections on DS performance in elderly individuals with a poorer educational background. ${ }^{21}$ This study aimed to investigate the effects of age, education, and gender on DS performance, and to provide normative information based on an analysis of a large, educationally diverse elderly population.

\section{METHODS}

\section{Study population}

Seven hundred and eighty-four healthy people aged 60-90 years were included in this study. Research participants were recruited from among elderly individuals who participated in a community service program for the early detection and management of dementia at 4 centers located in Seoul (two public health center and two dementia or memory clinics) from January 2003 to November 2010. All participants lived independently in the community. Informed consent was obtained from each participant according to the procedures approved by the institutional review board of each center.

Psychiatrists with advanced training in neuropsychiatry and dementia research examined all participants according to the protocol in the Korean Version of the Consortium to Established a Registry for Alzheimer's disease (CERAD) clinical assessment battery. ${ }^{22}$ The battery consisted of a standardized clinical interview on demographic information, cognitive and functional status, drug inventory, depression and medical history, a cognitive state examination including the six-item Korean version of the Short Blessed test ${ }^{23}$ and a general physical and neurological examination. In addition, they interviewed reliable informants to acquire accurate information regarding cognitive and functional changes and medical history of the participants. A panel consisting of four psychiatrists with expertise in dementia research made the clinical decisions including dementia diagnosis. This panel reviewed all available raw data from the clinical evaluation.

All participants in the present sample satisfied strict inclusion criteria. Candidates with dementia or another serious medical, psychiatric, or neurological disorder that could affect mental function were excluded. Psychiatrists diagnosed dementia using the criteria detailed in the Diagnostic and Statistical Manual of Mental Disorders, fourth edition. ${ }^{24}$ All participants possessed adequate hearing, although some required a hearing aid. Individuals with minor physical abnormalities (e.g., diabetes with no serious complications, essential hypertension, mild hearing loss, etc.) were included in the study.

\section{Measurements}

The DS in the standardized version of the Wechsler Adult Intelligence Scale-Revised ${ }^{11}$ was used in the present study. Trained psychologists administered the DS at each of the four sites. The DS was presented beginning with a length of 3 in forward or 2 in backward. In the DS forward, the participant had to listen to a digit span that keep to the speed of one digit per second and repeat it forward. On the contrary to DS forward, in the DS backward, the participant had to listen and repeat span backward. Two trials were presented at each length. Test was halted when participant failed to either trial at equal digit length.

\section{Statistical analysis}

Stepwise multiple linear regression analysis was used to assess the relative contributions of age, education, and gender on test scores. Age and education were entered as continuous variables and gender was coded as 0 or 1 for female and male, respectively.

A series of $2 \times 5 \times 2$ analyses of variance (ANOVA) was also performed to determine any main effects and interaction of age (60-74, 75-90 years), education (0-3, 4-6, 7-9, 10-12, and $\geq 13$ years) and gender on the tests. Post hoc contrasts with Tukey's method were conducted when any effect of age, education and gender was determined to be significant by ANOVA at the $\mathrm{p}<0.05$ level.

\section{RESULTS}

\section{Demographic characteristics}

The demographic characteristics of 784 participants are presented in Table 1. The mean age of the male participants (71.8 years) was slightly higher than that of the female participants [ 70.5 years; $t(782)=-3.04, p<0.01]$. The mean years of education was also much higher in the male group (10.5 years) than in the female group [6.6 years; $t(782)=-10.67, \mathrm{p}<$ 0.001].

\section{Effects of age, education, and gender on test scores}

Stepwise multiple regression analysis revealed that age, education and gender affected the test scores significantly. Among the demographic variables, education accounted for the greatest proportion of the score variance of both DS forward and backward performances (Table 2). Education accounted for $29.8 \%$ and $28.3 \%$ of the variance for DS forward and backward scores, respectively. Age accounted for $1.1 \%$ and $0.6 \%$ and gender accounted for $0.8 \%$ and $0.6 \%$ of DS forward and backward scores, respectively.

Three-way ANOVA was also performed to determine any main effects or interactions among demographic variables on 
test scores. Age $[\mathrm{F}(1,769)=13.18, \mathrm{p}<0.001]$, education $[\mathrm{F}(4$, $769)=30.69, \mathrm{p}<0.001]$ and gender $[F(1,769)=6.40, \mathrm{p}<0.05]$ were found to have significant effects on DS forward scores. Education $[\mathrm{F}(4,769)=28.65, \mathrm{p}<0.001]$ and gender $[\mathrm{F}(1,769)$ $=7.39, p<0.01]$ were found to have significant effects on DS backward scores. As shown in Table 3, no interaction between age, education and gender was found for DS forward test, however ANOVA's revealed significant interaction between education and gender for DS backward test.

Because education was found to affect scores of DS forward and backward, educational groups (i.e., 0-3, 4-6, 7-9, 10-12, $\geq 13$ years of education) were compared by using the post hoc contrasts. In terms of DS forward, significant differences were found between the $0-3$ year group and all $\geq 4$ year groups (i.e., $4-6,7-9,10-12$, $\geq 13$ years), between the $4-6$ and $10-12$ year groups, and between the $4-6$ and $\geq 13$ year group, whereas no significant differences were observed between the 4-6 and $7-9$, and between the 10-12 and $\geq 13$ year group. In term of

Table 1. Demographic characteristics of participants

\begin{tabular}{cccc}
\hline & Male & Female & Total \\
\hline Number & 266 & 518 & 784 \\
Age (yr) & $71.8 \pm 6.3^{*}$ & $70.5 \pm 6.1$ & $71.0 \pm 6.2$ \\
$60-69$ & $109(41.0)^{\dagger}$ & $238(45.9)$ & $347(44.3)$ \\
$70-79$ & $120(45.1)$ & $242(46.7)$ & $362(46.2)$ \\
$80-90$ & $37(13.9)$ & $38(7.3)$ & $75(9.6)$ \\
Education (yr) & $10.5 \pm 4.8$ & $6.6 \pm 4.9$ & $7.9 \pm 5.2$ \\
$0-3$ & $17(6.4)$ & $154(29.7)$ & $171(21.8)$ \\
$4-6$ & $57(21.4)$ & $158(30.5)$ & $215(27.4)$ \\
$7-9$ & $44(16.5)$ & $62(12.0)$ & $106(13.5)$ \\
$10-12$ & $65(24.4)$ & $92(17.8)$ & $157(20.0)$ \\
$13-$ & $83(31.2)$ & $52(10.0)$ & $135(17.2)$ \\
\hline
\end{tabular}

${ }^{*}$ result represents mean \pm standard deviation, ${ }^{\dagger}$ number (percent)

Table 2. Stepwise multiple linear regression of age, education and gender on digit span (DS) score

\begin{tabular}{lrrrrc}
\hline \multicolumn{1}{c}{ Variables } & $\mathrm{B}$ & $\mathrm{SE}(\mathrm{B})$ & $\beta$ & \multicolumn{1}{c}{$\Delta \mathrm{R}^{2}$} & $\mathrm{p}$ \\
\hline DS-forward score & & & & & \\
$\quad$ Education & 0.24 & 0.02 & 0.49 & 29.8 & 0.000 \\
$\quad$ Age & -0.05 & 0.01 & -0.12 & 1.1 & 0.000 \\
$\quad$ Gender & 0.51 & 0.17 & 0.10 & 0.8 & 0.003 \\
DS-backward score & & & & & \\
$\quad$ Education & 0.16 & 0.01 & 0.49 & 28.3 & 0.000 \\
Age & -0.03 & 0.01 & -0.09 & 0.6 & 0.003 \\
Gender & 0.32 & 0.12 & 0.09 & 0.6 & 0.008 \\
\hline
\end{tabular}

Age and education were entered as continuous variables, and sex was coded as 0 and 1 for female and male, respectively. B: regression coefficient, $\mathrm{SE}(\mathrm{B})$ : standard error of $\mathrm{B}, \beta$ : standardized regression coefficient, $\Delta R^{2}$ : percent variance explained by each variable
DS backward, significant differences were found between the $0-3$ year group and all $\geq 4$ year groups (i.e., $4-6,7-9,10-12$, $\geq 13$ years), between the $4-6$ year group and all $\geq 7$ year groups (i.e., $7-9,10-12, \geq 13$ years), and between the $7-9$ and $\geq 13$ year group, whereas no significant differences were observed between the 7-9 and 10-12, and between the 10-12 and $\geq 13$ year group.

\section{Normative data}

On the basis of the results for the effects of demographic variables, we decided to stratify DS forward and backward scores by age, education and gender (Table 4). Tables composed of age strata with midpoint ages occurring at 15 -year intervals (i.e., 67 and 82 years of age, respectively for two strata) were developed as shown in Table 4 . The educational groups were divided into three strata (i.e., $0-3,4-9$, and $\geq 10$ years of education) for DS forward and DS backward scores. Strata of education were determined considering the results from the post hoc contrasts between the five educational groups, and the number of participants within each cell. The normative scores of the DS stratified by demographic variables were shown in the forms of a mean, a standard deviation, a median and a range of the 5th percentile (Table 4).

\section{DISCUSSION}

The present investigation was conducted to examine the effect of demographic factors on the performance of the DS and to provide normative information in a large and educationally diverse elderly population to allow clinicians and researchers to interpret test results better. Lower educational level, older age, and female gender were associated with poorer performances of both DS forward and backward. Based on the results for the influence of demographic variables on DS perfor-

Table 3. Analysis of variance for main effects and interactions between education, age, and gender on digit span score

\begin{tabular}{|c|c|c|c|}
\hline \multicolumn{2}{|c|}{ Main effect } & \multicolumn{2}{|c|}{ Interaction } \\
\hline Variable & $\mathrm{F}$ & Variable & $\mathrm{F}$ \\
\hline \multicolumn{4}{|c|}{ DS-forward score } \\
\hline Education & $30.689^{* * *}$ & Education $\times$ age & 0.997 \\
\hline Age & $13.179^{* * *}$ & Education $\times$ gender & 0.605 \\
\hline Gender & $6.401^{*}$ & Age $\times$ gender & 0.207 \\
\hline \multicolumn{4}{|c|}{ DS-backward score } \\
\hline Education & $28.645^{* * *}$ & Education $\times$ age & 1.018 \\
\hline Age & 2.805 & Education $\times$ gender & $2.592^{*}$ \\
\hline Gender & $7.385^{* *}$ & Age $\times$ gender & 0.002 \\
\hline
\end{tabular}

Age is categorized as ' $60-74,75-90$ '; education as ' $0-3,4-6,7-9$, $10-12$, and $\geq 13$ years'; respectively. ${ }^{*} \mathrm{p}<0.05,{ }^{* *} \mathrm{p}<0.01,{ }^{* * *} \mathrm{p}<0.001$ by $2 \times 5 \times 2$ analysis of variance (ANOVA). DS: digit span 
Table 4. Normative data of digit span score: mean, standard deviation, median and range of the 5th percentile

\begin{tabular}{|c|c|c|c|c|c|c|c|c|c|c|c|c|}
\hline \multirow{3}{*}{ Age (years) } & \multicolumn{6}{|c|}{ DS forward } & \multicolumn{6}{|c|}{ DS backward } \\
\hline & \multicolumn{3}{|c|}{ Men } & \multicolumn{3}{|c|}{ Women } & \multicolumn{3}{|c|}{ Men } & \multicolumn{3}{|c|}{ Women } \\
\hline & $0-3$ & $4-9$ & $\geq 10$ & $0-3$ & $4-9$ & $\geq 10$ & $0-3$ & $4-9$ & $\geq 10$ & $0-3$ & $4-9$ & $\geq 10$ \\
\hline \multicolumn{13}{|l|}{$60-74$} \\
\hline $\mathrm{N}$ & 9 & 60 & 109 & 101 & 167 & 116 & 9 & 60 & 109 & 101 & 167 & 116 \\
\hline Mean & 3.89 & 5.52 & 7.58 & 3.66 & 4.93 & 6.86 & 3.56 & 4.47 & 5.42 & 2.86 & 4.12 & 5.05 \\
\hline SD & 2.15 & 2.48 & 2.49 & 1.73 & 2.02 & 2.02 & 0.88 & 1.56 & 1.55 & 1.43 & 1.46 & 1.54 \\
\hline 5th percentile & 1.00 & 2.00 & 3.00 & 2.00 & 2.00 & 4.00 & 2.00 & 2.00 & 3.00 & 0.00 & 2.00 & 2.85 \\
\hline Median & 4.00 & 5.00 & 8.00 & 3.00 & 5.00 & 7.00 & 4.00 & 4.00 & 6.00 & 3.00 & 4.00 & 5.00 \\
\hline \multicolumn{13}{|l|}{$75-90$} \\
\hline $\mathrm{N}$ & 8 & 41 & 39 & 53 & 53 & 28 & 8 & 41 & 39 & 53 & 53 & 28 \\
\hline Mean & 4.13 & 5.2 & 6.28 & 3.04 & 4.58 & 6.25 & 3.13 & 4.27 & 5.23 & 2.55 & 3.94 & 4.96 \\
\hline SD & 1.13 & 2.1 & 1.96 & 1.21 & 2.17 & 2.84 & 1.46 & 1.38 & 1.75 & 1.15 & 1.46 & 1.88 \\
\hline 5th percentile & 3.00 & 2.00 & 4.00 & 2.00 & 1.70 & 2.00 & 0.00 & 2.10 & 3.00 & 0.70 & 1.70 & 2.00 \\
\hline Median & 4.00 & 5.00 & 6.00 & 3.00 & 4.00 & 6.00 & 4.00 & 4.00 & 5.00 & 2.00 & 4.00 & 5.00 \\
\hline
\end{tabular}

SD: standard deviation, DS: digit span

mance, normative data were stratified by education, age and gender.

The significant influence of education on DS performances found in our study has already been reported by many previous studies. ${ }^{13,16,18,21,25,26}$ In regard of the degree of influences, however, there are some differences between studies. Some studies ${ }^{13,16}$ showed relatively small education effect $\left(\mathrm{R}^{2}\right.$ : about $5-8 \%)$, while other ones ${ }^{18,21}$ had bigger education effect $\left(\mathrm{R}^{2}\right.$ : greater than 23\%) like ours. This discrepancy among studies probably relates to the range of educational levels of study participants. The studies for subjects with very narrow range of educational background showed relatively small educational influence on both DS forward and backward performance, ${ }^{13,16}$ whereas those for the subjects with wide range of educational background like ours had greater education effect. $^{18,21}$

In terms of age effect on the DS, our findings were in line with those from most of previous studies. ${ }^{13,16,18,21,25}$ Similar to the degree of education effect above mentioned, however, the magnitude of age effect was also very diverse probably depending on the age distribution of study participants. The studies including young adults as well as older individuals revealed greater age influence $\left(R^{2} \text { : about } 10 \%\right)^{16,25}$ compared to those including only older subjects like ours ( $\mathrm{R}^{2}$ : about less than $1 \%) .{ }^{21} \mathrm{~A}$ study conducted only for oldest old individuals (age range 85-95 years) did not even show any age effect for both DS subtests. ${ }^{26}$

In our study, male performed significantly better than female in both DS forward and backward test, but the degree of gender effect was not so big ( $\mathrm{R}^{2}$ : only $0.8 \%$ for DS forward and $0.6 \%$ for DS backward). Although some previous studies also reported small but significant gender effect on both DS subtests or on DS backward performance, ${ }^{16,18}$ other studies did not found any gender effect on DS performances. ${ }^{21,25} \mathrm{Giv}$ en very small effect size, statistical power issue related to sample size as well as population characteristics may partially explain the difference between studies.

In addition to the main effects of education and gender, ANOVA revealed an interaction between gender and education for the DS backward test indicating that DS backward scores of women decline more steeply than that of men with decreasing educational level. The better performance on the DS backward test by poorly educated male elderly than female elderly individuals might be explained by differences in their social roles. Male elderly persons with little formal education were more likely to have opportunities for intellectual stimulation via occupational activities than poorly educated female elderly persons who are usually devoted to housework, as indicated in our previous work. ${ }^{27}$

In the present study, normative data was stratified by age, education and gender considering the effect of demographic variables on DS performance. We were able to provide accurate normative data with adequate numbers of subjects for most normative subgroups. However, sample numbers of male with very low educational level (i.e., $0-3$ years of education in Table 4) was still limited in size. Therefore, users should exercise caution when the test scores of such individuals are interpreted.

The study participants were recruited from mainly Seoul area, so it is hard to regard these elderly as representative of whole Korean elderly. However, the cognitive test score of Korean elderly is not associated with place of residence, and after 
controlling the effect of age and education, the difference between different area usually disappears. ${ }^{28}$ Moreover, there are lots of elderly in Seoul who were moved from rural area, so study participants in this study might cover both characteristics of urban and rural area. ${ }^{29}$

In conclusion, our results on the DS performances suggest that both attention and working memory are influenced by age, education and gender. Moreover, education had a greater effect than age and gender. We provide reasonably comprehensive normative data of the DS for an educationally diverse elderly population. Given most previously published norms have been largely based on the highly educated elderly, ${ }^{16,25}$ the normative information presented in this report can be very helpful to properly interpret DS scores of older people, especially those with a poorer educational background.

\section{Acknowledgments}

This study was supported by a grant from the Korea Healthcare Technology R \& D Project, Ministry of Health, Welfare \& Family Affairs, Republic of Korea (grant No. A092145).

\section{REFERENCES}

1. Banken JA. Clinical utility of considering digits forward and digits backward as separate components of the Wechsler Adult Intelligence Scale-Revised. J Clin Psychol 1985;41:686-691.

2. Johnstone B, Erdal K, Stadler MA. The Relationship between the Wechsler Memory Scale Revised (WMS-R) Attention Index and Putative Measures of Attention. J Clin Psychol Med Set 1995;2:195-204.

3. Lezak MD. Norms for Growing Older. Dev Neuropsychol 1987;3:1-12.

4. Ryan JJ, Lopez SJ, Paolo AM. Digit span performance of persons 75-96 years of age: Base rates and associations with selected demographic variables. Psychol Assess 1996;8:324-327.

5. Orsini A, Chiacchio L, Cinque M, Cocchiaro C, Schiappa O, Grossi D. Effects of age, education and sex on two tests of immediate memory: a study of normal subjects from 20 to 99 years of age. Percept Mot Skills 1986;63:727-732.

6. Anstey KJ, Smith GA. Interrelationships among biological markers of aging, health, activity, acculturation, and cognitive performance in late adulthood. Psychol Aging 1999;14:605-618.

7. Botwinick J, Storandt M, Berg L. A Longitudinal, behavioral study of senile dementia of the Alzheimer type. Arch Neurol 1986;43:1124-1127.

8. Austin MP, Ross M, Murray C, O'Carroll RE, Ebmeier KP, Goodwin GM. Cognitive function in major depression. J Affect Disord 1992; 25:21-29.

9. Mathias CW, Greve KW, Bianchini KJ, Houston RJ, Crouch JA. Detecting malingered neurocognitive dysfunction using the reliable digit span in traumatic brain injury. Assessment 2002;9:301-308.

10. Kurt P, Yener G, Oguz M. Impaired digit span can predict further cognitive decline in older people with subjective memory complaint: a preliminary result. Aging Ment Health 2011;15:364-369.

11. Wechsler D. WMS-R: Wechsler Memory Scale-Revised: Manual. San Antonio, TX: Psychological Corp., Harcourt Brace Jovanovich;1987.

12. Woods DL, Kishiyama MM, Yund EW, Herron TJ, Edwards B, Poliva O, et al. Improving digit span assessment of short-term verbal memory. J Clin Exp Neuropsychol 2010;4:1-11.

13. Gregoire J, Van der Linden M. Effect of age on forward and backward digit spans. Aging Neuropsychol Cogn 1997;4:140-149.

14. Palmer BW, Boone KB, Lesser IM, Wohl MA. Base rates of "impaired" neuropsychological test performance among healthy older adults. Arch Clin Neuropsychol 1998;13:503-511.

15. Kaufman AS, Mclean JE, Reynolds CR. Sex, race, residence, region, and education differences on the 11 WAIS-R subtests. J Clin Psychol 1988; 44:231-248.

16. Anstey KJ, Matters B, Brown AK, Lord SR. Normative data on neuropsychological tests for very old adults living in retirement villages and hostels. Clin Neuropsychol 2000;14:309-317.

17. Ardila A, Rosselli M. Neuropsychological characteristics of normal aging. Dev Neuropsychol 1989;5:307-320.

18. Pena-Casanova J, Quinones-Ubeda S, Quintana-Aparicio M, Aguilar M, Badenes D, Molinuevo JL, et al. Spanish Multicenter Normative Studies (NEURONORMA Project): norms for verbal span, visuospatial span, letter and number sequencing, trail making test, and symbol digit modalities test. Arch Clin Neuropsychol 2009;24:321-341.

19. Singh D, Joska JA, Goodkin K, Lopez E, Myer L, Paul RH, et al. Normative scores for a brief neuropsychological battery for the detection of HIV-associated neurocognitive disorder (HAND) among South Africans. BMC Res Notes 2010;3:28.

20. Ivnik RJ, Malec JF, Smith GE, Tangalos EG, Petersen RC, Kokmen E, et al. Mayos Older Americans normative studies: WAIS-R norm for ages 56 to 97. Clin Neuropsychol 1992;6:1-30.

21. Kang YW, Chin JH, Na DL. A normative study of the digit span test for the elderly. Korean J Clin Psychol 2002;21:911-922.

22. Lee JH, Lee KU, Lee DY, Kim KW, Jhoo JH, Kim JH, et al. Development of the Korean version of the Consortium to Establish a Registry for Alzheimer's Disease Assessment Packet (CERAD-K): clinical and neuropsychological assessment batteries. J Gerontol B Psychol Sci Soc Sci 2002;57:P47-P53.

23. Lee DY, Yoon JC, Lee KU, Jhoo JH, Kim KW, Lee JH, et al. Reliability and validity of the Korean Version of Short Blessed Test (SBT-K) as a dementia screening instrument. J Korean Neuropsychiatr Assoc 1999; 38:1365-1375.

24. American Psychiatric Association. Diagnostic and Statistical Manual of Mental Disorders, 4th Edition. Washington, DC: American Psychiatric Association; 1994.

25. Fine EM, Kramer JH, Lui LY, Yaffe K, Study of Osteoporotic Fractures SOF Research Group. Normative data in women aged 85 and older: verbal fluency, digit span, and the CVLT-II short form. Clin Neuropsychol 2012;26:18-30.

26. Monaco M, Costa A, Caltagirone C, Carlesimo GA. Forward and backward span for verbal and visuo-spatial data: standardization and normative data from an Italian adult population. Neurol Sci 2013;34:749754.

27. Lee DY, Lee KU, Lee JH, Kim KW, Jhoo JH, Kim SY, et al. A normative study of the CERAD neuropsychological assessment battery in the Korean elderly. J Int Neuropsychol Soc 2004;10:72-81.

28. Yeo HY, Lee KY, Lee GH, Jhoo JH, Kim KW, Lee JH, et al. The effects of sociodemographic variables on MMSE - K scores of the elderly in urban and rural area. Kor J Psychopathol 1998;7:72-80.

29. Lee DY, Lee KY, Lee JH, Kim KU, Jhoo JH, Youn JC, et al. A normative study of the Mini-Mental State Examination in the Korean elderly. J Korean Neuropsychiatr Assoc 2002;41:512-525. 